\title{
Synthesis of 1,8-Naphthyridines by the Ionic Liquid-Catalyzed Friedlander Reaction and Application in Corrosion Inhibition
}

\author{
Ying San, Jian Sun,* Hong Wang, Zhao-Hui Jin, and Hua-Jing Gao* \\ Cite This: ACS Omega 2021, 6, 28063-28071 \\ Read Online
}

ACCESS

山ll Metrics \& More

回国 Article Recommendations

Supporting Information

ABSTRACT: A several of basic ionic liquids (ILs) were synthesized as green solvents and catalysts for the preparation of 1,8-naphthyridyl derivatives via the Friedlander reaction. [Bmmim] $[\mathrm{Im}]$ exhibited remarkable catalytic activity to achieve the synthetic targets, and the reaction conditions were optimized. The model product 2,3-diphenyl-1,8naphthyridine (1,8-Nap), with carboxyethylthiosuccinic acid (CETSA) to form an IL corrosion inhibitor ([1,8-Nap][CETSA $]$ ), and its corrosion inhibition performance for Q235 steel in $1 \mathrm{M} \mathrm{HCl}$ were researched by weight loss measurements, and the results showed that the inhibition efficiency was $96.95 \%$ when the concentration of $[1,8-\mathrm{Nap}]$ [CETSA] was 1 $\mathrm{mM}$ at $35{ }^{\circ} \mathrm{C}$. The electrochemical test verified that [1,8-Nap] [CETSA] acted as a mixed-type inhibitor but mainly exhibited cathodic behavior. The inhibitor adsorbed on the metal surface was further proved by surface topography analysis.

\section{INTRODUCTION}

1,8-Naphthyridine and its derivatives exhibit excellent optical performance, $^{1-3}$ various biological activities, ${ }^{4}$ and flexible coordination ability, ${ }^{5-7}$ which led them to be widely used in many fields. As a kind of fluorescent biological probe, they have the characteristic of recognizing specific DNA sequences; ${ }^{8-10}$ good catalytic activity and thermal stability can be observed when they are used as a ligand for metal ions. $^{11-13}$ Meanwhile, a large number of 1,8-naphthyridyl compounds own significant anti-inflammatory and antibacterial activity; especially, as anticancer agents, they have shown promising potential. ${ }^{14-16}$ Because 1,8-naphthyridyl derivatives have a broad range of applicability in many fields, there has been increasing attention toward developing efficient methods for 1,8-naphthyridine synthesis.

The common synthesis methods of 1,8-naphthyridine are Skraup, Combes, Pfitzinger, Conrad-Limpach, and Friedlander reactions over the past few decades; ${ }^{17-19}$ among them, the Friedlander reaction is considered to be the simplest method with higher yields. ${ }^{20-22}$ However, the Friedlander reaction system uses hazardous and often expensive acid or base catalysts; the catalysts cannot be reused, making it difficult for the reaction to realize industrialization. Thus, a convenient, rapid, environmentally friendly, and high-yielding synthetic method was designed using ionic liquids (ILs) as reaction media as well as promoters to synthesize 1,8 naphthyridine without any added catalyst or solution because ILs have interesting properties such as a wide liquidus range, ${ }^{23}$ good solubility of solutes, ${ }^{24}$ low saturated vapor pressure, $^{25}$ and excellent catalytic activity and recyclability. ${ }^{26}$ 1,8-naphthyridyl complexes with unique structures have been extensively applied in pharmaceuticals, ${ }^{27,28}$ molecular recognition, ${ }^{29}$ fluorescence sensors, ${ }^{30,31}$ as well as in the fields of organic chemistry. ${ }^{32}$ However, as far as we know, there are almost no reports about their use as a corrosion inhibitor. Therefore, we proposed 1,8-naphthyridine as a cation to synthesize an efficient corrosion inhibitor, and a new application of 1,8-naphthyridine was explored. In this study, ILs were used as reaction media to synthesize 1,8naphthyridine by the Friedlander reaction and the influence of the IL type, reaction time, and reaction temperature on the reaction was investigated. The substrate compatibility of the reaction system under the optimal conditions was also researched. Then, 2,3-diphenyl-1,8-naphthyridine as the model substrate was used as the cation with the anion carboxyethylthiosuccinic acid (CETSA) to synthesize IL [1,8Nap][CETSA] (Scheme 1), ${ }^{33}$ and its corrosion inhibition performance were researched by weight loss measurements, electrochemical tests, and surface topography analysis.

Received: August 1, 2021

Accepted: October 5, 2021

Published: October 15, 2021 
Scheme 1. Synthesis of $[1,8-N a p][$ CETSA]<smiles>O=C(O)CCSC(CC(=O)O)C(=O)O</smiles>

\section{RESULTS AND DISCUSSION}

2.1. pH Measurement of ILs. The acid-base characterization of ILs is of great significance for application in the field of catalysis. By testing the acidity and alkalinity, the relationship between the anion and cation structure with alkalinity can be studied to guide the synthesis of ILs. ${ }^{34}$ Hence, the $\mathrm{pH}$ values of ILs with the concentration of 0.1 and $0.01 \mathrm{~mol} \cdot \mathrm{L}^{-1}$ were measured at $25^{\circ} \mathrm{C}$, and the results showed that alkalinity of the ILs $[\mathrm{Bmmim}][\mathrm{Im}]>[\mathrm{Bmmim}]$ $\left[\mathrm{OC}_{2} \mathrm{H}_{5}\right]>[\mathrm{Bmmim}][\mathrm{OH}]>[\mathrm{Bmmim}]\left[\mathrm{OCH}_{3}\right]$ at the same concentration.

2.2. Thermogravimetric Analysis of ILs. The thermal decomposition temperature of the ILs was measured by thermogravimetric analysis (TGA), and the results are shown in Figure 1. In addition, the values of $T_{\mathrm{d} 5}$ and $T_{\mathrm{d} 10}\left(T_{\mathrm{d} 5}\right.$ and

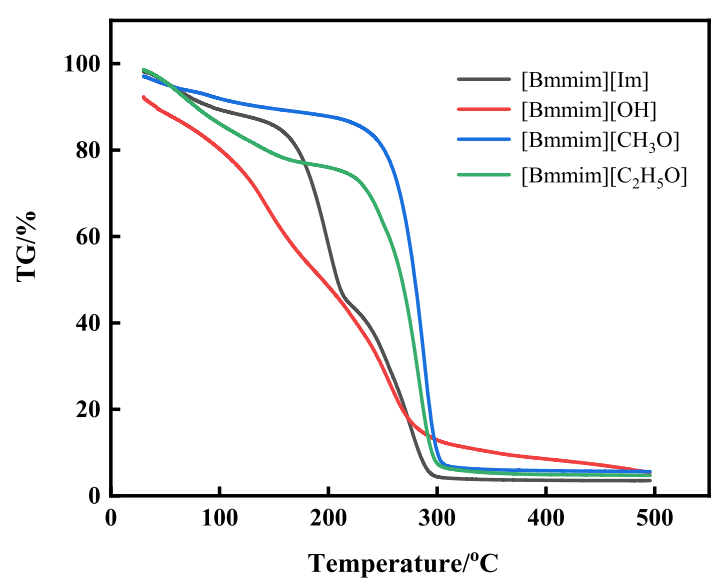

Figure 1. TGA data of four basic ILs.

$T_{\mathrm{d} 10}$ are the thermogravimetric temperatures of 5 and $10 \%)^{35-37}$ and char yield of ILs are listed in Table 1 . The

\section{Table 1. TGA Data of the ILs}

\begin{tabular}{lccc}
\multicolumn{1}{c}{ samples } & $T_{\mathrm{d} 5}\left({ }^{\circ} \mathrm{C}\right)$ & $T_{\mathrm{d} 10}\left({ }^{\circ} \mathrm{C}\right)$ & char yield $(\%)$ \\
{$[$ Bmmim $][\mathrm{Im}]$} & 64 & 112 & 3.57 \\
{$[\mathrm{Bmmim}][\mathrm{OH}]$} & 56 & 85 & 5.80 \\
{$[\mathrm{Bmmim}]\left[\mathrm{OC}_{2} \mathrm{H}_{5}\right]$} & 60 & 84 & 4.76 \\
{$[\mathrm{Bmmim}]\left[\mathrm{OCH}_{3}\right]$} & 94 & 207 & 5.59 \\
\hline
\end{tabular}

results display the percentage mass loss with temperature when the ILs are heated to a maximum temperature of 500 ${ }^{\circ} \mathrm{C}$. Obviously, the initial weight loss peak appears at about $100{ }^{\circ} \mathrm{C}$ in Figure 1, and the $T_{\mathrm{d} 5}$ and $T_{\mathrm{d} 10}$ are between 56-94 and $84-207{ }^{\circ} \mathrm{C}$, respectively, in Table 1 , which may be caused by volatilization of water in the ILs and thus does not represent true decomposition. According to the thermogravi- metric curve, there is a strong weight loss peak in the range of $150-300{ }^{\circ} \mathrm{C}$, which may be caused by the decomposition of cations and anions of the ILs. Compared with other ILs, $[\mathrm{Bmmim}][\mathrm{OH}]$ has a lower thermal decomposition temperature, and it is speculated that a smaller volume of $\mathrm{OH}^{-}$ decomposes first. The results indicate that the four ILs have great thermal stability in the catalytic stage.

2.3. Synthesis of $1,8-$ Naphthyridine and Its Derivatives. Availing the ILs as the catalysts and solvents, the Friedlander reaction used 2-amino-3-pyridinecarboxaldehyde (a) and 2-phenylacetophenone (b) as the model substrates to investigate the catalytic competency of the ILs (Table 2).

Table 2. Optimization of the Reaction Conditions Using the Model Friedlander Reaction between 2-Amino-3pyridinecarboxaldehyde (a) and 2-Phenylacetophenone (b) ${ }^{a}$

$\begin{array}{ccccccc}\text { entry } & \text { catalyst } & (\mathrm{h}) & T\left({ }^{\circ} \mathrm{C}\right) & \begin{array}{c}\mathrm{IL} \\ (\mathrm{mL})\end{array} & \begin{array}{c}\text { molar ratio } \\ (\mathbf{a} / \mathbf{b})\end{array} & \text { yield } \\ 1 \%)\end{array}$

${ }^{a}$ Reaction conditions: $\mathbf{a}$ and $\mathbf{b}(1 \mathrm{mmol})$ were dissolved in ILs.

When the initial experiments were carried out with equimolar amounts of $\mathbf{a}$ and $\mathbf{b}$ in different ILs $(5 \mathrm{~mL})$ at $80{ }^{\circ} \mathrm{C}$ for 24 $\mathrm{h},[\mathrm{Bmmim}][\mathrm{Im}]$ was found to be superior to others (entries $1-4)$; perhaps, $[\mathrm{Bmmim}][\mathrm{Im}]$ has a stronger basicity. Moreover, we noted that only $5 \mathrm{~mL}$ of $[\mathrm{Bmmim}][\mathrm{Im}]$ (entry 1 ) could obtain the product with great yield (entries 1 
and 14-16). Then, encouraged by the stirring results, we further investigated the influence of other reaction conditions, such as reaction temperature (entries 1 and 5-7), reaction time (entries 1 and 8-10) and molar ratio (1 and 11-13). Surprisingly, the desired product was formed with $90 \%$ yield with $\mathbf{a}$ and $\mathbf{b}(0.6: 1)$ in the presence of $[\mathrm{Bmmim}][\mathrm{Im}](5$ $\mathrm{mL}$ ) at $80{ }^{\circ} \mathrm{C}$ for $24 \mathrm{~h}$ (entry 12 ).

At the end of the reaction, $[\mathrm{Bmmim}][\mathrm{Im}]$ was easily recovered from the mixture by a simple extraction with deionized water, and its reusability was researched under the same reaction conditions. It was noticed that the recovered catalyst was reused 4 times without significant loss of its catalytic activity (Figure 2).

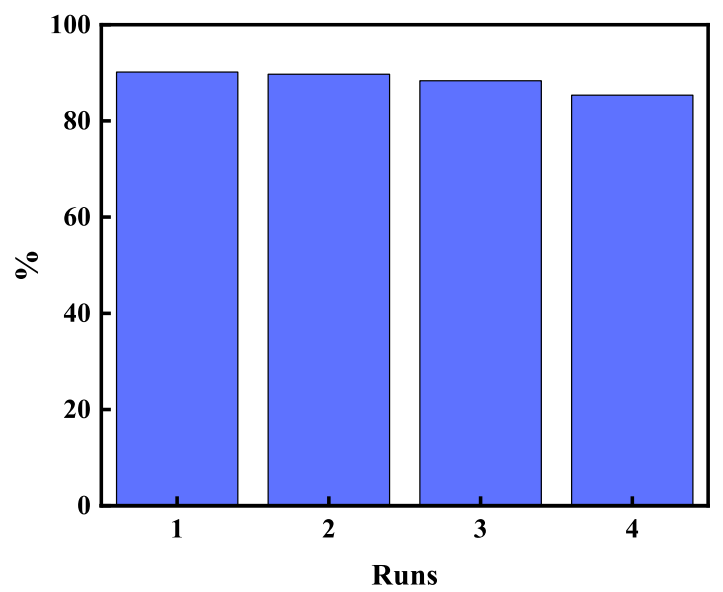

Figure 2. Recyclability of $[\mathrm{Bmmim}][\mathrm{Im}]$ for the synthesis of 2,3diphenyl-1,8-naphthyridine.

Thereafter, according to the suitable reaction conditions of this method, the substrate compatibility of the Friedlander reaction system was investigated, so 2-amino-3-pyridinecarboxaldehyde was reacted with various acyclic and cyclic ketones (aldehydes) to produce a range of 1,8-naphthyridyl derivatives, and the results are displayed in Table 3. As shown, the reaction was successful with cyclic ketones such as cyclohexanone and 2-methylcyclohexanone (entries 1 and 2), and it achieved the desired products with moderate yield. Likewise, polycyclic 1,8-naphthyridine $3 \mathbf{g}-\mathbf{h}$ were obtained under basic IL conditions with a simple workup. Frequently, the Friedlander reaction with unsymmetrical ketones may undergo two modes of cyclization, producing different natures of catalysts. Surprisingly, the $[\mathrm{Bmmim}][\mathrm{Im}]$-catalyzed Friedlander reaction with unsymmetrical ketones (aldehydes) generated exclusive products in excellent yields (entries 3 and 5). All desired products of substituted 1,8-naphthyridine were obtained and characterized by ${ }^{1} \mathrm{H}$ NMR and ${ }^{13} \mathrm{C}$ NMR spectra.

2.4. Mechanism. According to all the experiments, we put forward a possible reaction mechanism of the Friedlander reaction shown in Scheme 2. First, the ketone (aldehyde) with $\alpha-\mathrm{H}$ (a) generates carbanion (c) under alkaline conditions, and (c) undergoes a condensation reaction with carbonyl-containing aldehyde (d) to form an intermediate product (f), and finally, the produce ring is formed while the carbon-nitrogen double bond generates $(\mathbf{h}) .^{22,38}$

\section{APPLICATION OF 1,8-NAPHTHYRIDINES}

3.1. Weight Loss Measurements. In order to know the corrosion protection behavior with different concentrations of $[1,8$-Nap] [CETSA], we performed the weight loss measurements for Q235 steel in $1 \mathrm{M} \mathrm{HCl}$ for $24 \mathrm{~h}$ at $35^{\circ} \mathrm{C}$, and the results are shown in Table 4 . All measurements were repeated 3 times under the same condition. The corrosion rate $(V)$, inhibition efficiency $(\eta)$, and surface coverage $(\theta)$ were calculated from the following equations. ${ }^{33}$

$$
\begin{aligned}
& V=\frac{\Delta m}{s t} \\
& \eta(\%)=\frac{V_{0}-V_{\text {inh }}}{V_{0}} \times 100 \\
& \theta=\frac{V_{0}-V_{\text {inh }}}{V_{0}}
\end{aligned}
$$

where $\Delta m$ represents the weight loss value of the Q235 steel sample after the weight loss measurement $(\mathrm{g}), t$ is the immersion time (h), $s$ is the immersed area of the steel sample $\left(\mathrm{m}^{2}\right), V_{0}$ and $V_{\text {inh }}$ are the corrosion rates without and with $[1,8-\mathrm{Nap}]\left[\right.$ CETSA], respectively $\left(\mathrm{g} \cdot \mathrm{m}^{-2} \cdot \mathrm{h}^{-1}\right)$.

It can be seen from Table 4 that the inhibition efficiency increased with the increase of [1,8-Nap][CETSA] and reached up to $96.95 \%$ when the concentration was $1 \mathrm{mM}$; probably, inhibitor molecules adsorbed on the Q235 steel's surface and excluded the corrosion media. Meanwhile, the inhibitor could affect either or both metal dissolution and hydrogen evolution processes. ${ }^{39}$ However, with the concentration of [1,8-Nap][CETSA] continuously increasing, the inhibition efficiency decreased slightly. Perhaps, this was due to the competitive adsorption of inhibitor molecules on the metal surface. Compared to the previous literature, $[1,8$ Nap][CETSA] and other corrosion inhibitors, such as choline-based and imidazolium-based ILs, showed excellent corrosion inhibition ability at high concentration, but $[1,8$ Nap][CETSA] exhibited better inhibition efficiency when it was at low concentration. ${ }^{39-42}$ This proves that $[1,8$ Nap][CETSA] ILs have significant application potential in the corrosion protection field.

3.2. Potentiodynamic Polarization Measurements. Potentiodynamic polarization curves for Q235 steel in $1 \mathrm{M}$ $\mathrm{HCl}$ in the absence and presence of different concentrations of $[1,8-\mathrm{Nap}]$ [CETSA $]$ at $35^{\circ} \mathrm{C}$ are shown in Figure 3. The inhibition efficiency $(\eta)$ and the degree of surface coverage $(\theta)$ were determined from eq 4 , and calculated parameters are gathered in Table 5, where $E_{\text {corr }}$ is the corrosion potential, and $I_{\text {corr }}^{0}$ and $I_{\text {corr }}$ are the corrosion current densities in the absence and presence of the inhibitor, respectively. ${ }^{43,44}$

$$
\eta(\%)=\theta \times 100=\left[\frac{I_{\text {corr }}^{0}-I_{\text {corr }}}{I_{\text {corr }}^{0}}\right] \times 100
$$

As can be seen in Figure 3, all the anodic and cathodic Tafel curves moved to the lower current direction and the curves were almost parallel to the blank curve upon the addition of the inhibitor; this indicated that the inhibitor reduced the anodic dissolution of steel and delayed the cathodic reaction of hydrogen evolution, but the inhibition mechanism had not been altered. If the change in the $E_{\text {corr }}$ value in the presence of the inhibitor is more than $\pm 85 \mathrm{mV}$ related to the $E_{\text {corr }}$ value of blank, the inhibitor may be 
Table 3. Preparation of 1,8-Naphthyridyl Derivatives ${ }^{a}$

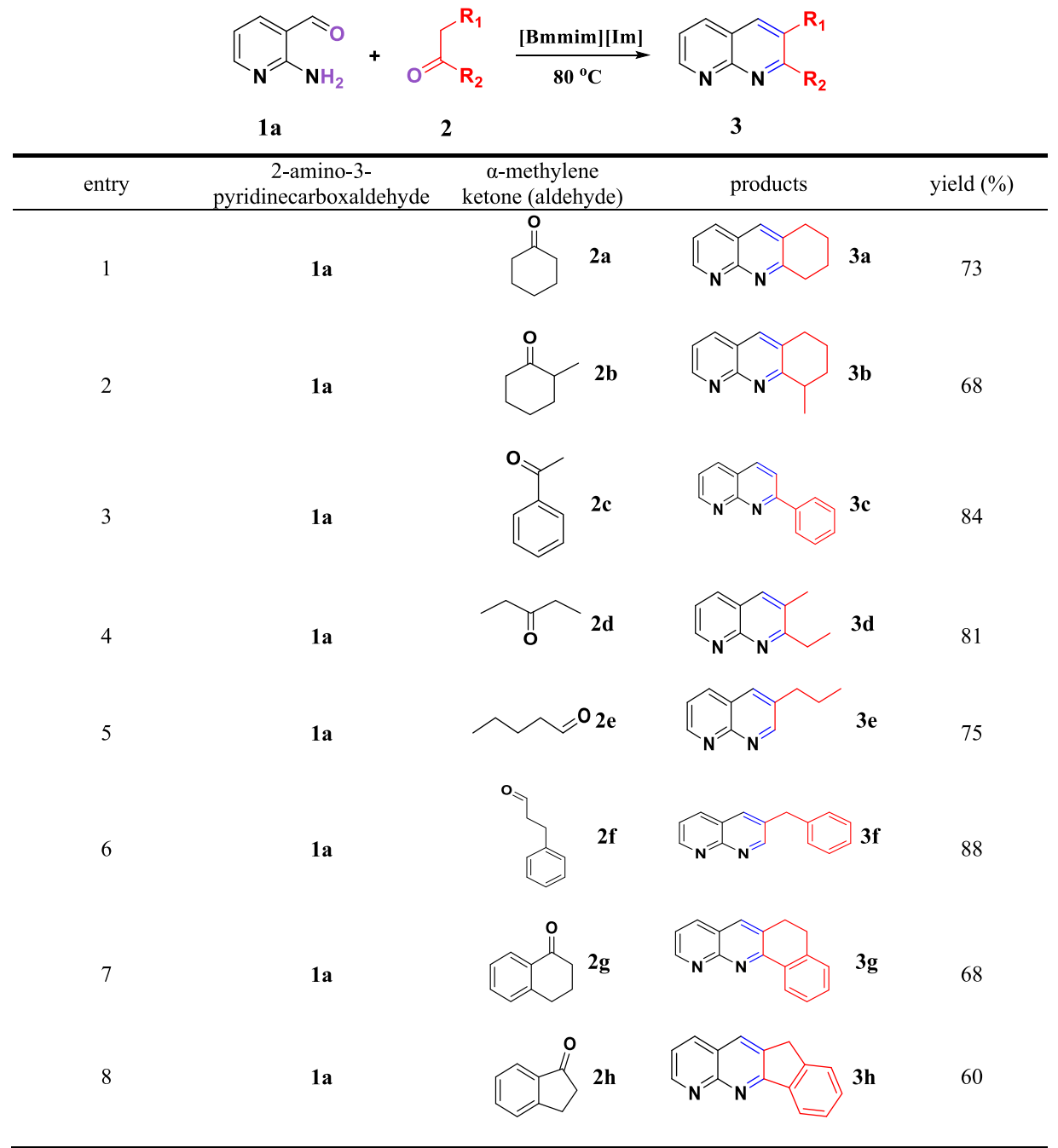

${ }^{a}$ Reaction conditions: 1a $(0.6 \mathrm{mmol})$ and $2(1 \mathrm{mmol})$ were dissolved in $5 \mathrm{~mL}$ of $[\mathrm{Bmmim}][\mathrm{Im}]$ at $50{ }^{\circ} \mathrm{C}$ for $24 \mathrm{~h}$.

Scheme 2. Proposed Mechanism for the Synthesis of 1,8Naphthyridyl Derivatives

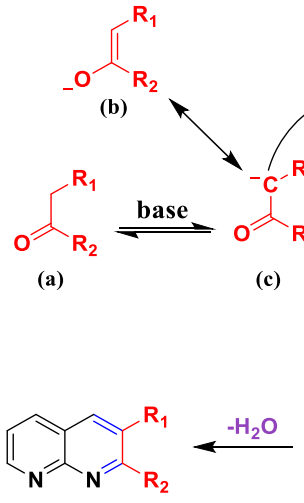

(h)

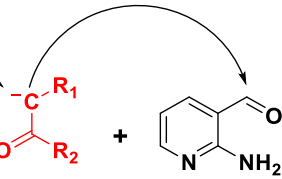

(d)

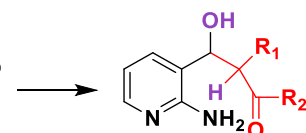

(e) $-\mathrm{H}_{2} \mathrm{O}$ (f)

considered as a cathodic or anodic type. The inhibitor can be deemed as a mixed type when the shift is not more than 85 $\mathrm{mV}$ in $E_{\text {corr }}{ }^{45-47}$ The data in Table 5 show that $E_{\text {corr }}$ shifts slightly toward the negative direction and the displacement was less than $85 \mathrm{mV}$ with the inhibitor existence, which

Table 4. Corrosion Parameters of Q235 Steel Immersed in $1 \mathrm{M} \mathrm{HCl} \mathrm{Solution} \mathrm{in} \mathrm{the} \mathrm{Absence} \mathrm{and} \mathrm{Presence} \mathrm{of}$ Different Concentrations of [1,8-Nap] [CETSA] for $24 \mathrm{~h}$ at $35{ }^{\circ} \mathrm{C}$

\begin{tabular}{lrcc}
$\mathrm{C}(\mathrm{mM})$ & $V\left(\mathrm{~g} \cdot \mathrm{m}^{-2} \mathrm{~h}^{-1}\right)$ & $\eta(\%)$ & $\theta$ \\
$\quad$ blank & $12.55 \pm 0.04$ & & \\
0.1 & $0.50 \pm 0.02$ & 95.99 & 0.9599 \\
1 & $0.38 \pm 0.02$ & 96.95 & 0.9695 \\
2.5 & $0.42 \pm 0.05$ & 96.58 & 0.9658 \\
5 & $0.47 \pm 0.03$ & 96.18 & 0.9618 \\
\hline
\end{tabular}

means that $[1,8$-Nap] [CETSA] is a mixed-type inhibitor but mainly exhibits cathodic behavior.

3.3. Electrochemical Impedance Spectroscopy. Electrochemical impedance spectroscopy (EIS) is a method for finding out the mechanism involved in the corrosion process. The different processes occurring at the electrode/electrolyte interface can be simulated with equivalent electrical circuits, and these models are used to adjust the experimental impedance maps and extract parameter values. ${ }^{48}$ The Nyquist and Bode plots of Q235 steel immersed in $1 \mathrm{M} \mathrm{HCl}$ solution without and with various concentrations of [1,8-Nap]- 


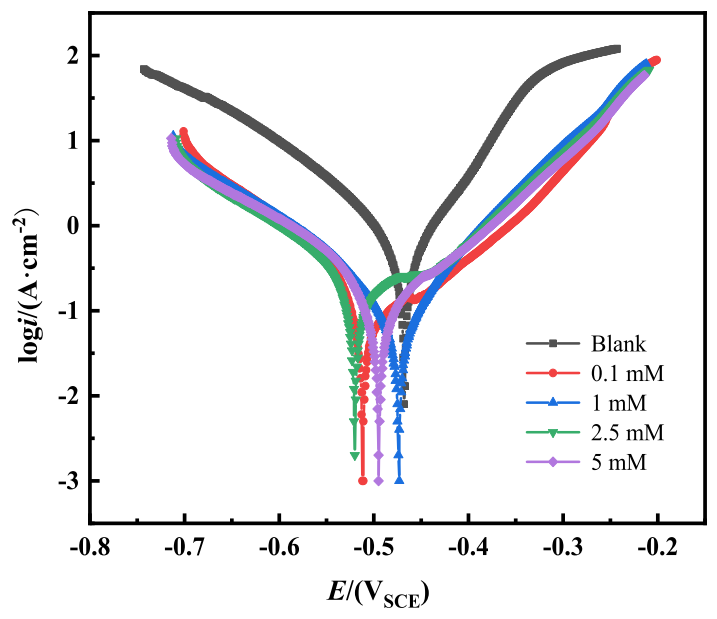

Figure 3. Polarization curves of Q235 steel in $1 \mathrm{M} \mathrm{HCl}$ in the absence and presence of different concentrations of [1,8-Nap][CETSA].

Table 5. Polarization Parameters for Q235 Steel in $1 \mathrm{M}$ $\mathrm{HCl}$ Solution in the Absence and Presence of Different Concentrations of $[1,8-\mathrm{Nap}]$ [CETSA]

\begin{tabular}{llrlc} 
medium & $E_{\text {corr }}(\mathrm{mV})$ & $I_{\text {corr }}\left(\mu \mathrm{A} \cdot \mathrm{cm}^{-2}\right)$ & $\eta(\%)$ & $\theta$ \\
\hline blank & $-457 \pm 3$ & $64.7 \pm 0.02$ & & \\
0.1 & $-464 \pm 4$ & $10.13 \pm 0.03$ & 84.34 & 0.8434 \\
1 & $-458 \pm 1$ & $7.00 \pm 0.02$ & 89.18 & 0.8918 \\
2.5 & $-465 \pm 3$ & $9.05 \pm 0.03$ & 86.01 & 0.8601 \\
5 & $-459 \pm 2$ & $11.22 \pm 0.01$ & 82.65 & 0.8265
\end{tabular}

[CETSA] at $35{ }^{\circ} \mathrm{C}$ are represented in Figures 4 and 5, and the equivalent electrical circuits are shown in Figure 6.

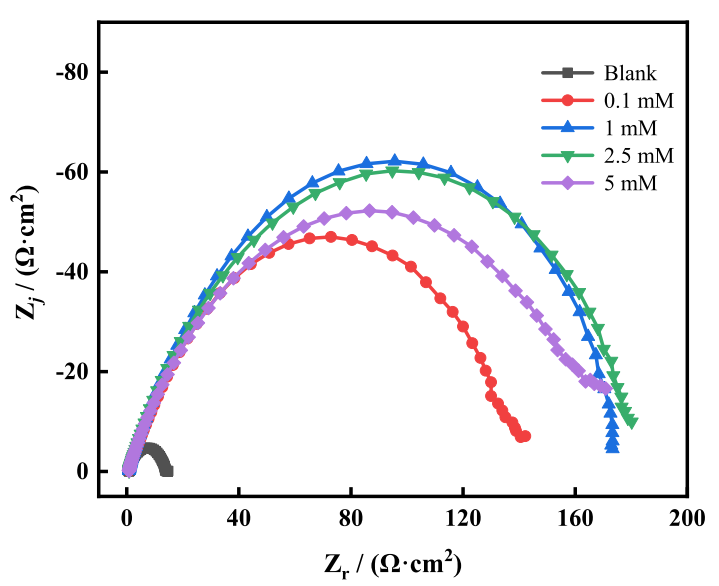

Figure 4. Nyquist plot of Q235 steel in $1 \mathrm{M} \mathrm{HCl}$ solution without and with different concentrations of $[1,8-\mathrm{Nap}][\mathrm{CETSA}]$.

As seen in the Nyquist spectra, the diameter of the semicircle increases in the presence of [1,8-Nap] [CETSA], which shows that the inhibitor molecules adsorbed onto the surface of Q235 steel and hindered the charge-transfer process to decrease the corrosion rate. However, the shape of the capacitor ring did not alter, indicating that the corrosion inhibition mechanism did not change. From the Bode plots (Figure 5), it was apparently seen that the values of the phase angle increased with the addition of $[1,8$-Nap] [CETSA] due to the formation of a significant covering layer on the electrode's surface.

Table 6 lists a series of EIS measurement parameters such as the solution resistance $\left(R_{\mathrm{s}}\right)$, charge-transfer resistance $\left(R_{\mathrm{ct}}\right)$, electric double-layer capacitance $\left(C_{\mathrm{dl}}\right)$, and inhibition efficiency $(\eta)$. Because of inhibitor's adsorption mode and the difference in surface roughness, a constant-phase element was employed rather than an ideal double-layer capacitor in order to gain a more accurate model. ${ }^{42}$ The values of inhibition efficiency and double-layer capacitance were computed from eqs 5 and 6 , respectively. ${ }^{49}$

$$
\begin{aligned}
& \eta(\%)=\left(\frac{R_{\mathrm{ct}}-R_{\mathrm{ct}}^{0}}{R_{\mathrm{ct}}}\right) \times 100 \\
& C_{\mathrm{dl}}=\left(Q^{1 / n} R_{\mathrm{ct}}^{1-n / n}\right)
\end{aligned}
$$

where $R_{\mathrm{ct}}$ and $R_{\mathrm{ct}}^{0}$ are the resistances of charge transfer with and without $[1,8-\mathrm{Nap}][\mathrm{CETSA}]$, respectively.

It is observed that $R_{\mathrm{ct}}$ values increase significantly in the presence of $[1,8-\mathrm{Nap}][\mathrm{CETSA}]$, while the $C_{\mathrm{dl}}$ value decrease is probably attributed to the replacement of water and $\mathrm{HCl}$ molecules with large dielectric constants of [1,8-Nap][CETSA] molecules; ${ }^{50}$ these results illustrate that a protective layer formed on the metal surface to inhibit the corrosion process. Meanwhile, the EIS measurement showed that $\eta$ was over $90 \%$, and inhibitor molecules can be stably adsorbed on the surface of Q235 steel.

3.4. Surface Topography Analysis. Scanning electron microscopy (SEM) and energy-dispersive spectroscopy (EDS) are useful techniques used to detect and analyze the morphology and elemental composition of the Q235 steel surface in different situations. ${ }^{51,52}$ The SEM and EDS graphs of Q235 steel immersed in $1 \mathrm{M} \mathrm{HCl}$ solution without or with $1 \mathrm{mM}\left[1,8\right.$-Nap] [CETSA] for $24 \mathrm{~h}$ at $35^{\circ} \mathrm{C}$ are presented in Figure 7. In Figure 7a, the freshly polished mechanical marks on the surface of the carbon steel can be observed. In the absence of inhibitors (Figure 7b), the Q235 steel surface became rough and uneven due to the corrosive attack by $\mathrm{HCl}$ solution. Figure 7c shows that Q235 steel was protected with [1,8-Nap][CETSA], and the steel surface appeared smooth and uniform without distinct corrosion pits, and even signs of sandpaper polishing could be clearly seen. The phenomenon suggested that the inhibitor molecules on the surface of Q235 steel resulted in the formation of a protective film, confirming the previous experimental results.

The EDS spectrum was used to further analyze the surface elemental composition of Q235 steel. On comparing Figure $7 \mathrm{~b}$ with Figure $7 \mathrm{a}$, the existence of $\mathrm{Cl}$ atoms covering the metal surface can be observed, which can be attributed to the formation of corrosion products. The EDS spectra in the corrosion-inhibiting medium (Figure 7c) pointed out the presence of $\mathrm{O}$ linked to the $[1,8$-Nap] [CETSA] adsorbed on the metal surface, forming a protective layer.

\section{CONCLUSIONS}

In summary, we have successfully conceived a green method for the synthesis of 1,8-naphthyridyl derivatives by the Friedlander reaction, which used a series of basic ILs such as $[\mathrm{Bmmim}][\mathrm{Im}]$ as an efficient catalyst under solvent-free conditions. The optimized reaction conditions of this method were as follows: $\alpha$-methylene carbonyl compounds and 2amino-3-pyridinecarboxaldehyde at a molar ratio of 1:0.6; 

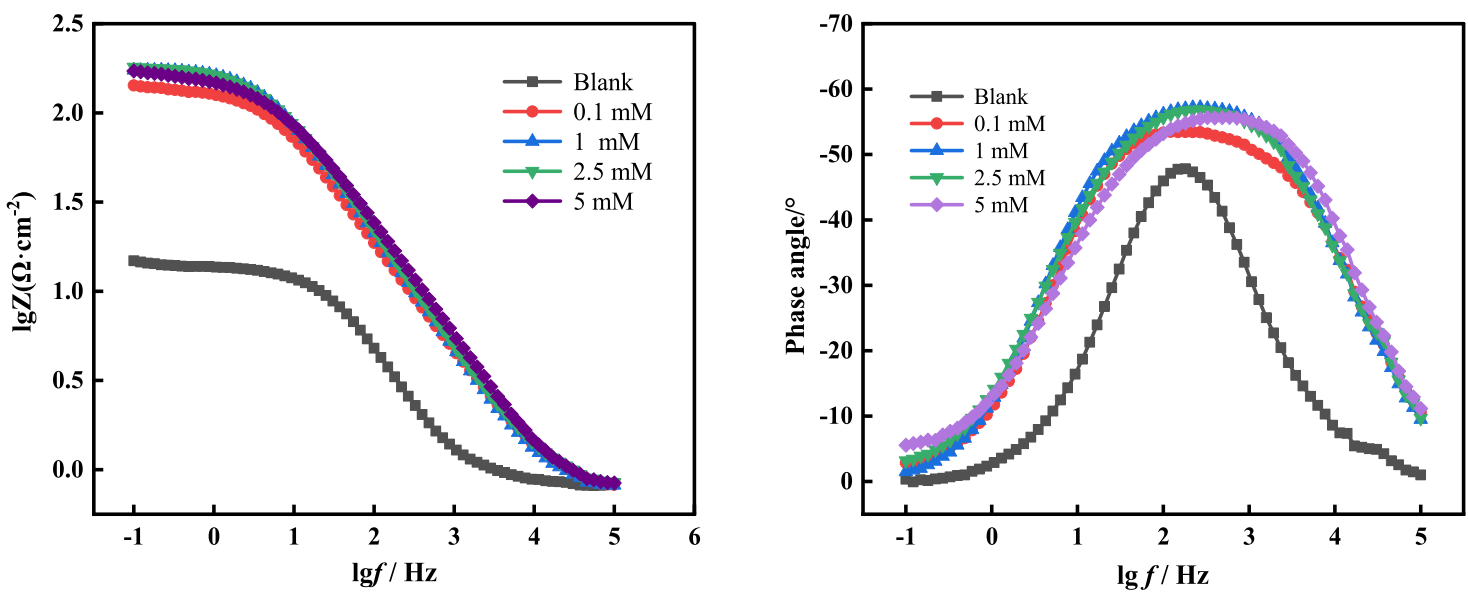

Figure 5. Bode plots for Q235 steel without and with different concentrations of $[1,8$-Nap][CETSA] in $1 \mathrm{M} \mathrm{HCl}$ solution.

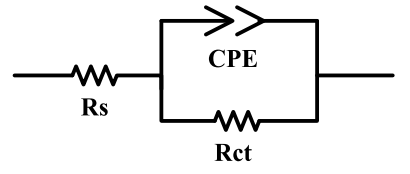

Figure 6. Equivalent circuit used to fit impedance spectra.

they were dissolved in $5 \mathrm{~mL}$ of $[\mathrm{Bmmim}][\mathrm{Im}]$ at $80{ }^{\circ} \mathrm{C}$ for $24 \mathrm{~h}$, and the IL was reused at 4 times without significant loss of its catalytic activity. Therefore, we proposed a possible mechanism based on the experimental results. This method not only provides a simple, excellent, and moderate way to generate 1,8-naphthyridyl derivatives but also to reduce environmental pollution. In addition, the model substrate 2,3diphenyl-1,8-naphthyridine with CETSA forms a corrosion inhibitor [1,8-Nap][CETSA]. The inhibition performance of [1,8-Nap][CETSA] on Q235 steel in $1 \mathrm{M} \mathrm{HCl}$ were studied via weight loss tests, electrochemical measurements, and surface topography analysis. The consequence suggested that inhibitor molecules adsorbed on the surface of the metal and formed a dense protective layer, which blocked the contact between metal and acid solution. At the same time, the results confirmed that $[1,8-\mathrm{Nap}][\mathrm{CETSA}]$ showed mixed corrosion inhibition but mainly exhibited cathodic behavior.

\section{EXPERIMENTAL SECTION}

5.1. Materials. 1,2-Dimethyl imidazole, bromobutane, imidazole, sodium methoxide, sodium ethanol, $\alpha$-methylene ketones (aldehydes), sodium hydroxide, and 2-amino-3pyridine formaldehyde were purchased from Shanghai Yi Heng Technology Co., Ltd. Ethyl acetate and petroleum ether were purchased from Beijing Chemical Plant. Hydrochloric acid was purchased from Tianjin Chemical Works. CETSA was synthesized in our lab.
5.2. Synthesis of Basic ILs. The basic ILs [Bmmim]$[\mathrm{Im}],[\mathrm{Bmmim}][\mathrm{OH}],[\mathrm{Bmmim}]\left[\mathrm{OC}_{2} \mathrm{H}_{5}\right]$, and $[\mathrm{Bmmim}]-$ $\left[\mathrm{OCH}_{3}\right]$ were prepared according to the reported procedures. ${ }^{53,54}$

5.3. Synthesis of 1,8-Naphthyridine. A mixture of $\alpha$ methylene carbonyl compounds and 2-amino-3-pyridinecarboxaldehyde in ILs was added into a Schlenk reaction bottle and magnetically stirred at about $80{ }^{\circ} \mathrm{C}$. After the reaction, the rection mixture was extracted by moderate ethyl ether and deionized water. The ethyl ether phase was collected, and then it was evaporated under a rotary evaporator to obtain the crude product. 1,8-Naphthyridine was separated using a specific volume ratio of the solvent (petroleum ether/ ethyl ether) by silica gel column chromatography.

5.4. Synthesis of [1,8-Nap][CETSA]. A total of $4.44 \mathrm{~g}$ of CETSA and $2.8 \mathrm{~g}$ of 2,3-diphenyl-1,8-naphthyridine were dissolved in $15 \mathrm{~mL}$ of methanol. The reaction mixture was stirred and heated to $50{ }^{\circ} \mathrm{C}$ for $5 \mathrm{~h}$. After the reaction, the mixture was distilled under vacuum to remove methanol and to obtain $[1,8-\mathrm{Nap}][\mathrm{CETSA}]$ with a yield of $91 \%$.

5.5. Weight Loss Measurements. The dimensions of the Q235 steel sample used for weight loss measurement were $25 \mathrm{~mm} \times 25 \mathrm{~mm} \times 1 \mathrm{~mm}$, and the steel pieces were polished, cleaned by deionized water, anhydrous ethanol, and acetone, dried in warm air, and then weighed for the test. The Q235 steel sample was immersed in $1 \mathrm{M} \mathrm{HCl}$ solution without or with different concentrations of the inhibitors at $35{ }^{\circ} \mathrm{C}$. After $24 \mathrm{~h}$, the immersed Q235 steel samples were washed and reweighed.

5.6. Electrochemical Measurements. Potentiodynamic polarization curves and EIS are two classical electrochemical techniques which were used to analyze the inhibition characteristics of $[1,8-\mathrm{Nap}]$ [CETSA] in $1 \mathrm{M} \mathrm{HCl}$ at $35^{\circ} \mathrm{C}$. Electrochemical experiments were carried out through a

Table 6. Impedance Parameters for Q235 Steel in $1 \mathrm{M} \mathrm{HCl}$ in the Presence and Absence of Different Concentrations of [1,8-Nap][CETSA]

$\begin{array}{lll}\text { medium } & R_{\mathrm{s}}\left(\Omega \mathrm{cm}^{2}\right) & R_{\mathrm{ct}}\left(\Omega \mathrm{cm}^{2}\right) \\ \text { blank } & 0.83 \pm 0.033 & 13.21 \pm 0.9 \\ 0.1 & 0.71 \pm 0.020 & 146.5 \pm 1.6 \\ 1 & 0.73 \pm 0.0091 & 188.7 \pm 2.0 \\ 2.5 & 0.70 \pm 0.03 & 185.2 \pm 1.1 \\ 5 & 0.67 \pm 0.015 & 168.6 \pm 2.8\end{array}$

$C_{\mathrm{dl}}\left(\mu \mathrm{F} \cdot \mathrm{cm}^{-2}\right)$
406.81
175.73
162.33
159.02
136.14

136.14

$\begin{array}{cl}n & \eta(\%) \\ 0.80 \pm 0.04 & \\ 0.70 \pm 0.03 & 91.16 \\ 0.70 \pm 0.03 & 92.99 \\ 0.71 \pm 0.01 & 92.86 \\ 0.70 \pm 0.02 & 92.16\end{array}$



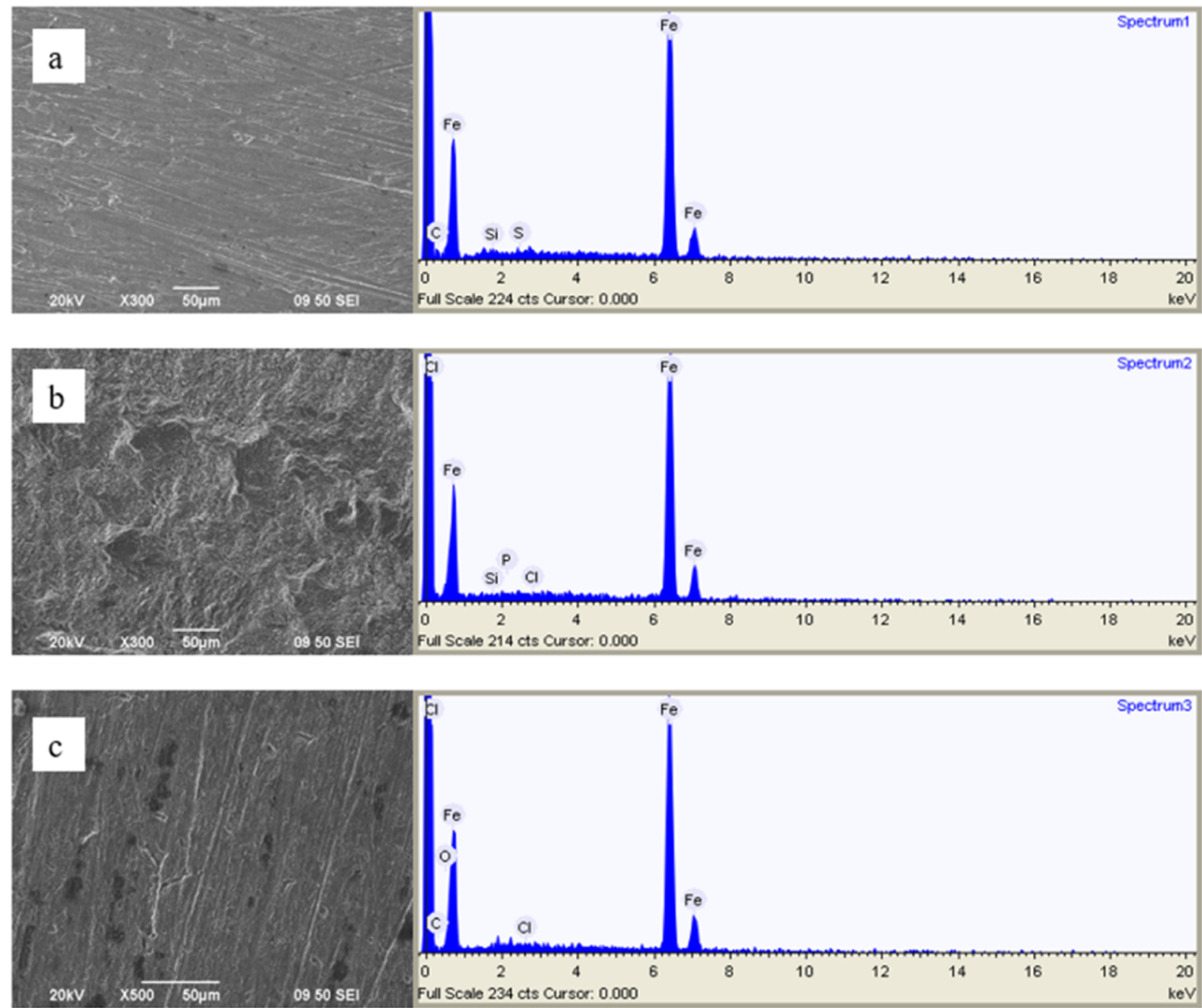

Figure 7. SEM images and EDS spectra of Q235 steel samples before (a) and after immersion in $1 \mathrm{M} \mathrm{HCl} \mathrm{without} \mathrm{(b)} \mathrm{and} \mathrm{with} \mathrm{(c)} 1 \mathrm{mM}$ [1,8-Nap][CETSA] for $24 \mathrm{~h}$ at $35^{\circ} \mathrm{C}$.

conventional three-electrode system, with the Q235 steel sample as a working electrode and saturated $\mathrm{Hg} / \mathrm{HgCl}_{2}$ and platinum sheet as reference and counter electrodes, respectively. The working electrode was immersed in $1 \mathrm{M}$ $\mathrm{HCl}$ solution for $30 \mathrm{~min}$ to ensure a stationary condition. Polarization curves were verified at a potential range of \pm 250 $\mathrm{mV}$ with a scan rate of $0.5 \mathrm{mV} \cdot \mathrm{s}^{-1}$. Impedance experiments were carried out in the frequency range from $100 \mathrm{kHz}$ to 100 $\mathrm{mHz}$ by using an amplitude of $15 \mathrm{mV}$. All experiments were replicated 3 times.

5.7. Characterization. The thermal stability of the IL was determined by TGA. Under the protection of nitrogen, the heating rate was $10{ }^{\circ} \mathrm{C} / \mathrm{min}$, and the test temperature range was $0-500{ }^{\circ} \mathrm{C}$. The alkalinity of the IL was determined by a $\mathrm{pH}$ meter, and the $\mathrm{pH}$ value of the IL of different concentrations was measured at $25{ }^{\circ} \mathrm{C}$. The structures of ILs, 1,8-naphthyridyl derivatives, and [1,8-Nap][CETSA] were confirmed by ${ }^{1} \mathrm{H}$ NMR, ${ }^{13} \mathrm{C}$ NMR, Fourier transform infrared spectroscopy, and high-resolution mass spectroscopy. The corrosion inhibition performance of $[1,8-\mathrm{Nap}]$ [CETSA] was determined by the electrochemical measurements without and with different concentrations of corrosion inhibitors at 35 ${ }^{\circ} \mathrm{C}$. SEM and EDS were used to study the surface morphology of the Q235 steel specimens $(10 \mathrm{~mm} \times 10$ $\mathrm{mm} \times 1 \mathrm{~mm}$ ) that were immersed in $1 \mathrm{M} \mathrm{HCl}$ solution in the absence and presence of $1 \mathrm{mM}$ [1,8-Nap][CETSA] for $24 \mathrm{~h}$ at $35{ }^{\circ} \mathrm{C}$. Potentiodynamic polarization curves and EIS were used to determine the corrosion inhibition characteristics of [1,8-Nap][CETSA] in $1 \mathrm{M} \mathrm{HCl}$ solution.

\section{ASSOCIATED CONTENT}

\section{(5) Supporting Information}

The Supporting Information is available free of charge at https://pubs.acs.org/doi/10.1021/acsomega.1c04103.

$\mathrm{pH}$ measurement of ILs and chemical structure characterization of Friedlander reaction products and ILs (PDF)

\section{AUTHOR INFORMATION}

\section{Corresponding Authors}

Jian Sun - Institute of Petrochemical Technology, Jilin Institute of Chemical Technology, Jilin 132022, China ○ orcid.org/0000-0001-5182-1632; Email: sunjian6225@ 126.com

Hua-Jing Gao - Institute of Petrochemical Technology, Jilin Institute of Chemical Technology, Jilin 132022, China; Email: huajing_gao@126.com 


\section{Authors}

Ying San - Institute of Petrochemical Technology, Jilin Institute of Chemical Technology, Jilin 132022, China

Hong Wang - Institute of Petrochemical Technology, Jilin Institute of Chemical Technology, Jilin 132022, China

Zhao-Hui Jin - Institute of Petrochemical Technology, Jilin Institute of Chemical Technology, Jilin 132022, China

Complete contact information is available at:

https://pubs.acs.org/10.1021/acsomega.1c04103

\section{Notes}

The authors declare no competing financial interest.

\section{ACKNOWLEDGMENTS}

We are grateful to the support from the Jilin Province Science and Technology Development Plan Project (20180201019SF) and the Doctor Startup Foundation of the Jilin Institute of Chemical Technology.

\section{REFERENCES}

(1) Krämer, C.; Leingang, S.; Hübner, O.; Kaifer, E.; Wadepohl, H.; Himmel, H.-J. Construction of copper chains with new fluorescent guanidino-functionalized naphthyridine ligands. Dalton Trans. 2016, 45, 16966-16983.

(2) Harada, N.; Karasawa, S.; Matsumoto, T.; Koga, N. Thermal Single Crystal to Single Crystal Transformation among Crystal Polymorphs in 2-Dimethylamino-5,7-bis(trifluoromethyl)-1,8-naphthyridine and in a 1-Quinoline Analogue. Cryst. Growth Des. 2013, $13,4705-4713$.

(3) Váradi, L.; Gray, M.; Groundwater, P. W.; Hall, A. J.; James, A. L.; Orenga, S.; Perry, J. D.; Anderson, R. J. Synthesis and evaluation of fluorogenic 2-amino-1,8-naphthyridine derivatives for the detection of bacteria. Org. Biomol. Chem. 2012, 10, 2578-2589.

(4) Ferrarini, P. L.; Mori, C.; Manera, C.; Martinelli, A.; Mori, F.; Saccomanni, G.; Barili, P. L.; Betti, L.; Giannaccini, G.; Trincavelli, L.; Lucacchini, A. A novel class of highly potent and selective $A_{1}$ adenosine antagonists: structure-affinity profile of a series of 1,8naphthyridine derivatives. J. Med. Chem. 2000, 43, 2814-2823.

(5) Du, M.-L.; Hu, C.-Y.; Wang, L.-F.; Li, C.; Han, Y.-Y.; Gan, X.; Chen, Y.; Mu, W.-H.; Huang, M. L.; Fu, W.-F. New members of fluorescent 1,8-naphthyridine-based $\mathrm{BF}_{2}$ compounds: selective binding of $\mathrm{BF}_{2}$ with terminal bidentate $\hat{\mathrm{N}} \hat{\mathrm{NO}}$ and $\hat{\mathrm{N}} \hat{\mathrm{CO}}$ groups and tunable spectroscopy propertiesr. Dalton Trans. 2014, 43, 1392413931.

(6) Casas, J. M.; Diosdado, B. E.; Forniés, J.; Martín, A.; Rueda, A. J.; Orpen, A. G. Synthesis of Binuclear Platinum Complexes Containing the Ligands 8-Naphthyridine, 2-Aminopyridine, and 7Azaindolate. An Experimental Study of the Steric Hindrance of the Bulky Pentafluorophenyl Ligands in the Synthesis of Binuclear Complexes. Inorg. Chem. 2008, 47, 8767-8775.

(7) Gan, X.; Chi, S.-M.; Mu, W.-H.; Yao, J.-C.; Quan, L.; Li, C.; Bian, Z.-Y.; Chen, Y.; $\mathrm{Fu}, \mathrm{W} .-\mathrm{F}$. $\mathrm{Cu}(\mathrm{I})$ and $\mathrm{Pb}(\mathrm{II})$ complexes containing new tris(7-naphthyridyl)methane derivatives: synthesis, structures, spectroscopy and geometric conversion. Dalton Trans. 2011, 40, 7365-7374.

(8) Takei, F.; Igarashi, M.; Hagihara, M.; Oka, Y.; Soya, Y.; Nakatani, K. Secondary-Structure-Inducible Ligand Fluorescence Coupled with PCR. Angew. Chem. 2009, 121, 7962-7964.

(9) Nakatani, K.; Horie, S.; Murase, T.; Hagihara, S.; Saito, I. Assessment of the sequence dependency for the binding of 2aminonaphthyridine to the guanine bulge. Bioorg. Med. Chem. 2003, 11, 2347-2353.

(10) Kuramoto, K.; Tarashima, N.; Hirama, Y.; Kikuchi, Y.; Minakawa, N.; Matsuda, A. New imidazopyridopyrimidine:naphthyridine base-pairing motif, $\operatorname{ImN}^{\mathrm{N}}: \mathrm{NaO}^{\mathrm{O}}$, consisting of a DAAD:ADDA hydrogen bonding pattern, markedly stabilize DNA duplexes. Chem. Commun. 2011, 47, 10818-10820.
(11) Zhang, H.-M.; Fu, W.-F.; Gan, X.; Xu, Y.-Q.; Wang, J.; Xu, Q.-Q.; Chi, S.-M. A flexible 1,8-naphthyridyl derivative and its $\mathrm{Zn}$ (II) complexes: synthesis, structures, spectroscopic properties and recognition of Cd(II). Dalton Trans. 2008, 6817-6824.

(12) Chang, Y.-H.; Liu, Z.-Y.; Liu, Y.-H.; Peng, S.-M.; Chen, J.-T.; Liu, S.-T. Palladium(II) complexes based on 1,8-naphthyridine functionalized $\mathrm{N}$-heterocyclic carbenes (NHC) and their catalytic activity. Dalton Trans. 2011, 40, 489-494.

(13) Yeo, B. R.; Hallett, A. J.; Kariuki, B. M.; Pope, S. J. A. The $\operatorname{Re}(\mathrm{I})$ coordination chemistry of a series of pyrido[2,3- $b$ ]pyrazinederived ligands: Syntheses, characterisation and crystal structures. Polyhedron 2010, 29, 1088-1094.

(14) Tsuzuki, Y.; Tomita, K.; Shibamori, K.-i.; Sato, Y.; Kashimoto, S.; Chiba, K. Synthesis and Structure-Activity Relationships of Novel 7-Substituted 1,4-Dihydro-4-oxo-1-(2-thiazolyl)-1,8-naphthyridine-3carboxylic Acids as Antitumor Agents. Part 2. J. Med. Chem. 2004, 47, 2097-2109.

(15) Tomita, K.; Tsuzuki, Y.; Shibamori, K.-i.; Tashima, M.; Kajikawa, F.; Sato, Y.; Kashimoto, S.; Chiba, K.; Hino, K. Synthesis and Structure-Activity Relationships of Novel 7-Substituted 1,4Dihydro-4-oxo-1-(2-thiazolyl)-1,8-naphthyridine-3-carboxylic Acids as Antitumor Agents. Part 1. J. Med. Chem. 2002, 45, 5564-5575. (16) Kumar, V.; Jaggi, M.; Singh, A. T.; Madaan, A.; Sanna, V.; Singh, P.; Sharma, P. K.; Irchhaiya, R.; Burman, A. C. 1,8Naphthyridine-3-carboxamide derivatives with anticancer and antiinflammatory activity. Eur. J. Med. Chem. 2009, 44, 3356-3362.

(17) Silva, D.; Chioua, M.; Samadi, A.; Carmo Carreiras, M.; Jimeno, M.-L.; Mendes, E.; Ríos, C. d. 1.; Romero, A.; Villarroya, M.; López, M. G.; Marco-Contelles, J. Synthesis and pharmacological assessment of diversely substituted pyrazolo[3,4-b]quinoline, and benzo $[b]$ pyrazolo $[4,3-g][1,8]$ naphthyridine derivatives. Eur. J. Med. Chem. 2011, 46, 4676-4681.

(18) Aribi, F.; Schmitt, E.; Panossian, A.; Vors, J.-P.; Pazenok, S.; Leroux, F. R. A new approach toward the synthesis of 2,4bis(fluoroalkyl)-substituted quinoline derivatives using fluoroalkyl amino reagent chemistry. Org. Chem. Front. 2016, 3, 1392-1415.

(19) Kouznetsov, V.; Mendez, L.; Gomez, C. Recent Progress in the Synthesis of Quinolines. Curr. Org. Chem. 2005, 9, 141-161.

(20) Xu, J.; Chen, Q.; Luo, Z.; Tang, X.; Zhao, J. N-Heterocyclic carbene copper catalyzed quinoline synthesis from 2-aminobenzyl alcohols and ketones using DMSO as an oxidant at room temperature. RSC Adv. 2019, 9, 28764-28767.

(21) Wu, J.; Xia, H.-G.; Gao, K. Molecular Iodine: A Highly Efficient Catalyst in the Synthesis of Quinolines via Friedländer Annulation. Org. Biomol. Chem. 2006, 4, 126-129.

(22) Shirini, F.; Yahyazadeh, A.; Mohammadi, K.; Khaligh, N. G. Solvent-free synthesis of quinoline derivatives via the Friedländer reaction using 1,3-disulfonic acid imidazolium hydrogen sulfate as an efficient and recyclable ionic liquid catalyst. C. R. Chim. 2014, 17, $370-376$.

(23) Wittmar, A. S. M.; Koch, D.; Prymak, O.; Ulbricht, M. Factors affecting the nonsolvent-induced phase separation of cellulose from ionic liquid-based solutions. ACS Omega 2020, 5, 27314-27322.

(24) Chiappe, C.; Pieraccini, D. Ionic liquids: solvent properties and organic reactivity. J. Phys. Org. Chem. 2005, 18, 275-297.

(25) Tariq, M.; Freire, M. G.; Saramago, B.; Coutinho, J. A. P.; Lopes, J. N. C.; Rebelo, L. P. N. Surface tension of ionic liquids and ionic liquid solutions. Chem. Soc. Rev. 2012, 41, 829-868.

(26) Palimkar, S. S.; Siddiqui, S. A.; Daniel, T.; Lahoti, R. J.; Srinivasan, K. V. Ionic liquid-promoted regiospecific Friedlander annulation: novel synthesis of quinolines and fused polycyclic quinolines. J. Org. Chem. 2003, 68, 9371-9378.

(27) Bennie, L. S.; Burton, P. M.; Morris, J. A. Synthesis of 7-aryl1,8-naphthyridines via addition of aryl boronic acids to 1,8naphthyridine $N$-oxides. Tetrahedron Lett. 2011, 52, 4799-4802.

(28) Roma, G.; Grossi, G.; Di Braccio, M.; Piras, D.; Ballabeni, V.; Tognolini, M.; Bertoni, S.; Barocelli, E. 1,8-Naphthyridines VII. New substituted 5 -amino $[1,2,4]$ triazolo $[4,3-a][1,8]$ naphthyridine-6-car- 
boxamides and their isosteric analogues, exhibiting notable antiinflammatory and/or analgesic activities, but no acute gastrolesivity. Eur. J. Med. Chem. 2008, 43, 1665-1680.

(29) Ferrand, Y.; Kendhale, A. M.; Garric, J.; Kauffmann, B.; Huc, I. Parallel and Antiparallel Triple Helices of Naphthyridine Oligoamides. Angew. Chem., Int. Ed. 2010, 49, 1778-1781.

(30) Lu, S.-H.; Selvi, S.; Fang, J.-M. Ethynyl-linked (pyreno)pyrrole-naphthyridine and aniline-naphthyridine molecules as fluorescent sensors of guanine via multiple hydrogen bondings. $J$. Org. Chem. 2007, 72, 117-122.

(31) Chahal, M. K.; Sankar, M. 1,8-Naphthyridinic fluorescent 'turn-on' and 'turn-off' chemosensors for detection of $\mathrm{F}^{-}$and $\mathrm{Hg}^{2+}$ ions mimicking INHIBIT molecular logic behaviour. Anal. Methods 2015, 7, 4552-4559.

(32) de Greef, T. F. A.; Ligthart, G. B. W. L.; Lutz, M.; Spek, A. L.; Meijer, E. W.; Sijbesma, R. P. The mechanism of ureidopyrimidinone:2,7-diamido-naphthyridine complexation and the presence of kinetically controlled pathways in multicomponent hydrogen-bonded systems. J. Am. Chem. Soc. 2008, 130, 5479-5486.

(33) Gao, H.; Xie, N.; Wang, H.; Chen, M.; Zhang, J.; Sun, J.; Jin, Z. Evaluation of corrosion inhibition performance of a novel ionic liquid based on synergism between cation and anion. New J. Chem. 2020, 44, 7802-7810.

(34) Chen, P. Synthesis and Basic Characterization of Basic Ionic Liquids; South China University of Technology, 2009.

(35) Mohamed, M. G.; Kuo, S. W.; Mahdy, A.; Ghayd, I. M.; Aly, K. I. Bisbenzylidene cyclopentanone and cyclohexanone-functionalized polybenzoxazine nanocomposites: Synthesis, characterization, and use for corrosion protection on mild steel. Mater. Today Commun. 2020, 25, 101418.

(36) Aly, K. I.; Mohamed, M. G.; Younis, O.; Mahross, M. H.; Abdel-Hakim, M.; Sayed, M. M. Salicylaldehyde azine-functionalized polybenzoxazine: Synthesis, characterization, and its nanocomposites as coatings for inhibiting the mild steel corrosion. Prog. Org. Coat. 2020, 138, 105385 .

(37) Mohamed, M. G.; Kuo, S.-W. Crown Ether-Functionalized Polybenzoxazine for Metal Ion Adsorption. Macromolecules 2020, 53, 2420-2429.

(38) Bandyopadhyay, P.; Prasad, G. K.; Sathe, M.; Sharma, P.; Kumar, A.; Kaushik, M. P. Titania Nanomaterials: Efficient and Recyclable Heterogeneous Catalysts for the Solvent-Free Synthesis of Poly-Substituted Quinolines via Friedlaender Hetero-Annulation. RSC Adv. 2014, 4, 6638-6645.

(39) Subasree, N.; Selvi, J. A. Imidazolium based ionic liquid derivatives; synthesis and evaluation of inhibitory effect on mild steel corrosion in hydrochloric acid solution. Heliyon 2020, 6, No. e03498.

(40) Cui, F.; Ni, Y.; Jiang, J.; Ni, L.; Wang, Z. Inhibiting Effect of Ionic Liquids on the Corrosion of Mild Steel in $\mathrm{H}_{2} \mathrm{~S}$ and $\mathrm{HCl}$ Solution. Chem. Eng. Technol. 2020, 43, 2041-2052.

(41) Verma, C.; Obot, I. B.; Bahadur, I.; Sherif, E.-S. M.; Ebenso, E. E. Choline based ionic liquids as sustainable corrosion inhibitors on mild steel surface in acidic medium: Gravimetric, electrochemical, surface morphology, DFT and Monte Carlo Simulation studies. Appl. Surf. Sci. 2018, 457, 134-149.

(42) Li, M.; Chen, Y.; Yang, W. 1-Vinyl-3-allyl Imidazolium Bromide as a New Corrosion Inhibitor for Carbon Steel in $1 \mathrm{M} \mathrm{HCl}$ Solution. Chemistry Select 2020, 5, 13511-13523.

(43) Mohamed, M. G.; Mahdy, A.; Obaid, R. J.; Hegazy, M. A.; Kuo, S.-W.; Aly, K. I. Synthesis and characterization of polybenzoxazine/clay hybrid nanocomposites for uv light shielding and anti-corrosion coatings on mild steel. J. Polym. Res. 2021, 28, 297.

(44) Macedo, R. G. M. d. A.; Marques, N. d. N.; Tonholo, J.; Balaban, R. d. C.; Balaban, R. C. B. Water-soluble carboxymethylchitosan used as corrosion inhibitor for carbon steel in saline medium. Carbohydr. Polym. 2019, 205, 371-376.

(45) Haque, J.; Srivastava, V.; Verma, C.; Quraishi, M. A. Experimental and quantum chemical analysis of 2-amino-3-((4-
((S)-2-amino-2-carboxyethyl)-1H-imidazole-2-yl)thio) propionic acid as new and green corrosion inhibitor for mild steel in $1 \mathrm{M}$ hydrochloric acid solution. J. Mol. Liq. 2017, 225, 848-855.

(46) Salhi, A.; Tighadouini, S.; El-Massaoudi, M.; Elbelghiti, M.; Bouyanzer, A.; Radi, S.; El Barkany, S.; Bentiss, F.; Zarrouk, A. Keto-enol heterocycles as new compounds of corrosion inhibitors for carbon steel in $1 \mathrm{M} \mathrm{HCl}$ : Weight loss, electrochemical and quantum chemical investigation. J. Mol. Liq. 2017, 248, 340-349.

(47) Anusuya, N.; Saranya, J.; Sounthari, P.; Zarrouk, A.; Chitra, S. Corrosion inhibition and adsorption behaviour of some bispyrimidine derivatives on mild steel in acidic medium. J. Mol. Liq. 2017, 225, 406-417.

(48) Thoume, A.; Elmakssoudi, A.; Left, D. B.; Benzbiria, N.; Benhiba, F.; Dakir, M.; Zahouily, M.; Zarrouk, A.; Azzi, M.; Zertoubi, M. Amino acid structure analog as a corrosion inhibitor of carbon steel in $0.5 \mathrm{M} \mathrm{H}_{2} \mathrm{SO}_{4}$ : Electrochemical, synergistic effect and theoretical studies. Chem. Data Coll. 2020, 30, 100586.

(49) Aly, K. I.; Mahdy, A.; Hegazy, M. A.; Al-Muaikel, N. S.; Kuo, S.-W.; Gamal Mohamed, M. Corrosion Resistance of Mild Steel Coated with Phthalimide-Functionalized Polybenzoxazines. Coatings 2020, 10, 1114.

(50) Ma, X.; Wang, J.; Xu, J.; Jing, J.; Li, J.; Zhu, H.; Yu, S.; Hu, Z. Sunflower Head Pectin with Different Molecular Weights as Promising Green Corrosion Inhibitors of Carbon Steel in Hydrochloric Acid Solution. Acs Omega 2019, 4, 21148-21160.

(51) Nkuna, A. A.; Akpan, E. D.; Obot, I. B.; Verma, C.; Ebenso, E. E.; Murulana, L. C. Impact of selected ionic liquids on corrosion protection of mild steel in acidic medium: Experimental and computational studies. J. Mol. Liq. 2020, 314, 113609.

(52) Aslam, R.; Mobin, M.; Huda; Obot, I. B.; Alamri, A. H. Ionic liquids derived from $\alpha$-amino acid ester salts as potent green corrosion inhibitors for mild steel in $1 \mathrm{M} \mathrm{HCl}$. J. Mol. Liq. 2020, $318,113982$.

(53) Girard, A.-L.; Simon, N.; Zanatta, M.; Marmitt, S.; Gonçalves, P.; Dupont, J. Insights on recyclable catalytic system composed of task-specific ionic liquids for the chemical fixation of carbon dioxide. Green Chem. 2014, 16, 2815.

(54) Liu, J.; Shi, L.; Chen, F.; Deng, W. J.; Fan, J. L.; Xu, G. W. High heat stable strong basic ionic liquid is used for the synthesis of dimethyl carbonate. Fine Chem. 2020, 37, 1438-1446. 